\title{
Comparison of oral nifedipine and oral labetalol as a single drug therapy for control of blood pressure in preeclampsia
}

\author{
Alpesh R. Patel*, Sneha R. Arora, Jalpa K. Bhatt
}

Department of Obstetrics and Gynecology, Dr. M. K. Shah Medical College and Research Centre, Ahmedabad, Gujarat, India

Received: 28 March 2020

Accepted: 29 April 2020

*Correspondence:

Dr. Alpesh R. Patel,

E-mail: dralpeshobgy@gmail.com

Copyright: (c) the author(s), publisher and licensee Medip Academy. This is an open-access article distributed under the terms of the Creative Commons Attribution Non-Commercial License, which permits unrestricted non-commercial use, distribution, and reproduction in any medium, provided the original work is properly cited.

\begin{abstract}
Background: Worldwide hypertension during pregnancy is a common cause of maternal and fetal morbidity and mortality. Effective control of blood pressure is one of the important steps in management of preeclampsia. Few drugs like nifedipine, labetalol, methyldopa, and hydralazine have acceptable high safety profile during pregnancy.

Methods: In this study 120 antenatal women with non-severe preeclampsia were compared by giving either nifedipine or labetalol as a single drug therapy for control of blood pressure. Various parameters like control of blood pressure, side effects of drugs, gestational age at the time of delivery, mode of delivery, any complication and perinatal outcome were assessed.

Results: In this study authors found that in both group, adequate control of blood pressure was achieved. This study shows slightly higher rate of pre term delivery and LSCS with labetalol and minimal side effects with nifedipine but difference in each group is insignificant.

Conclusions: Labetalol and nifedipine both the drugs are equally effective in reducing blood pressure and any of it can safely be used as a first choice of drug for management of hypertension in preeclampsia and it can be decided as per clinician's experience and familiarity with drug.
\end{abstract}

Keywords: Antihypertensive, Labetalol, Nifedipine, Non severe preeclampsia

\section{INTRODUCTION}

Hypertensive disorders of pregnancy are common cause of maternal and fetal morbidity and mortality. ${ }^{1}$ Severity of it ranges from mild form of hypertension to multi organ failure and even death. It affects approximately 5$10 \%$ of pregnancies and responsible for $14 \%$ of maternal death worldwide. ${ }^{2}$

Hypertension during pregnancy includes gestational hypertension, preeclampsia, eclampsia, chronic hypertension, and preeclampsia superimposed on chronic hypertension. ${ }^{3}$ Among this preeclampsia either alone or superimposed on chronic hypertension and eclampsia are majorly responsible for complications. ${ }^{4}$ Preeclampsia is defined as onset of hypertension (systolic blood pressure more than $140 \mathrm{mmHg}$ and/or diastolic blood pressure more than 90) in previously normotensive woman along with proteinuria (>300 mg/24 hours) with or without signs of end organ damage after 20 weeks of gestation. ${ }^{5}$

Women with preeclampsia have increased risk of developing renal failure, Liver impairment, disseminated intravascular coagulopathy, cardiovascular diseases, cerebral hemorrhage, abruptio placenta, IUGR, and pre term delivery. ${ }^{6}$ Early diagnosis of preeclampsia, regular antenatal check-up, appropriate management of hypertension and early intervention by delivery can significantly reduce these complications.

Effective control of hypertension is one of the important steps in the management of preeclampsia and if blood 
pressure is properly controlled then complications can be prevented and in turn maternal and fetal morbidity and mortality can be reduced significantly. Varieties of antihypertensive drugs are available but use in pregnancy is restricted for most of it and few drugs like nifedipine, labetalol, methyldopa, and hydralazine are permitted. ${ }^{6}$ out of which nifedipine is a calcium channel blocker that has been used in pregnancy without any major issue. But it can cause sudden drop in blood pressure causing hypotension and sometime reduction in uteroplacental perfusion. Nifedipine is also used as tocolytics in preterm labor pain. Labetalol lowers blood pressure by blocking $\alpha-1$ and $\beta$ adrenergic receptor and it preserves better uteroplacental perfusion. Labetalol has been shown to cause maternal hepatotoxicity but effect is minimal and reversible. Both the drugs are widely used in preeclampsia for control of blood pressure as a first line of drug therapy. So, authors have conducted randomized prospective comparative study of oral nifedipine and oral labetalol in non-complicating preeclampsia for assessment of their efficacy, safety and perinatal outcome.

\section{METHODS}

The present prospective randomized controlled study was conducted at GMERS Medical College, Dharpur, Patan, Gujarat from January 2015 to May 2016. Initially 135 women were enrolled in study from all women attending regular antenatal OPD according to inclusion and exclusion criteria.

\section{Inclusion criteria}

- Antenatal women with non-severe preeclampsia willing to attend the regular antenatal clinic and willing to get enrolled in study.

\section{Exclusion criteria}

- Patients with chronic hypertension, renal diseases, hepatic diseases, cardiac diseases
- $\quad$ Patients with severe preeclampsia and eclampsia.

Out of initially enrolled 135 women 10 women who needed multiple drug therapy for better control of hypertension were dropped from study in-between and 5 women were lost to follow up during study. Enrolled women diagnosed with non-severe preeclampsia were divided in two groups and were selected randomly for either nifedipine group (Group A) or labetalol group (Group B). At the end of study period data of total 120 women were present out of which 60 women from Group A and 60 women from Group B.

Group A 60 patients received tablet nifedipine with starting dose of $10 \mathrm{mg}$ orally twice a day and with blood pressure monitoring every 5 days and dose titrated till adequate control of blood pressure achieved. Group B 60 patients received tablet labetalol orally with starting dose of $100 \mathrm{mg}$ twice a day and with blood pressure monitoring every 5 days and dose titrated till adequate control of blood pressure achieved.

Patients were followed till delivery and blood pressure was monitored on every follow up. Side effects of drugs, gestational age at the time of delivery, mode of delivery, any complication and perinatal outcome were noted. And finally, data analysed by using appropriate statistical method to compare the two-treatment group.

\section{RESULTS}

Table 1 shows that in this study majority of patients $(51.6 \%)$ with preeclampsia were young ( $<25$ years), which shows high prevalence of preeclampsia in young women. And incidence in age group 26-30 years, 30-35 years and more than 35 years is $19.3 \%, 17.5 \%$ and $11.6 \%$ respectively.

Table 2 shows that in this study primigravida have higher rate of preeclampsia which was $54.1 \%$ whereas in second gravida it was $21.6 \%$ and in multi gravida prevalence was $24.1 \%$.

Table 1: Distribution of cases according to age.

\begin{tabular}{|lllllll|}
\hline Age & Group A & \multicolumn{3}{c}{ Group B } & Total & ( \\
& $\mathbf{N = 6 0}$ & $\mathbf{\%}$ & $\mathbf{N = 6 0}$ & $\mathbf{\%}$ & $\mathbf{N = 1 2 0}$ & $10 \%$ \\
\hline$<20$ years & 7 & $11.7 \%$ & 5 & $8.3 \%$ & 12 & $41.6 \%$ \\
\hline $21-25$ & 23 & $38.3 \%$ & 27 & $45 \%$ & 50 & $19.3 \%$ \\
\hline $26-30$ & 12 & $20 \%$ & 11 & $18.3 \%$ & 23 & $17.5 \%$ \\
\hline $30-35$ & 11 & $18.3 \%$ & 10 & $16.7 \%$ & 21 & $11.6 \%$ \\
\hline$>35$ & 7 & $11.7 \%$ & 7 & $11.7 \%$ & 14 & \\
\hline
\end{tabular}

Table 3 shows that in this study $28.3 \%$ patient had developed preeclampsia between 20-32 weeks of gestation while $54.2 \%$ had developed during 33 to 37 weeks of gestation and $17.5 \%$ had developed preeclampsia after term pregnancy. Table 4 shows that in Group A $78.3 \%$ patients had good desired control of blood pressure whereas in Group B $71.6 \%$ had good blood pressure and continued for expectant management. 
In this study total 25 patients out of 120 needed early termination either by induction of labour or by caesarean section due to development of severe preeclampsia.

Table 2: Distribution of cases according to parity.

\begin{tabular}{|lllllll|}
\hline Parity & Group A & \multicolumn{3}{c|}{ Group B } & Total & N \\
\hline G1 & N=60 & \% & N=60 & \% & N=120 & \% \\
\hline G2 & 34 & $56.6 \%$ & 31 & $51.6 \%$ & 65 & $54.1 \%$ \\
\hline G3 & 12 & $20 \%$ & 14 & $23.3 \%$ & 26 & $21.6 \%$ \\
\hline$>$ G4 & 8 & $13.3 \%$ & 7 & $11.6 \%$ & 15 & $12.5 \%$ \\
\hline
\end{tabular}

Table 3: Distribution of cases according to gestational age at the time of onset of preeclampsia.

\begin{tabular}{|lllllll|}
\hline $\begin{array}{l}\text { Gestational age } \\
\text { (in weeks) }\end{array}$ & Group A & \multicolumn{3}{c|}{ Group B } & \multicolumn{3}{c|}{ Total } \\
\hline $20-32$ & $\mathbf{N}=\mathbf{6 0}$ & $\mathbf{\%}$ & $\mathbf{N = 6 0}$ & $\mathbf{\%}$ & $\mathbf{N = 1 2 0}$ & $\mathbf{\%}$ \\
\hline $33-37$ & 15 & $25 \%$ & 19 & $31.6 \%$ & 34 & $28.3 \%$ \\
\hline$>37$ & 34 & $56.6 \%$ & 31 & $51.6 \%$ & 65 & $54.2 \%$ \\
\hline
\end{tabular}

Table 4: Result on continuous follow-up.

\begin{tabular}{|c|c|c|c|c|c|c|c|}
\hline \multirow{2}{*}{ Result } & \multicolumn{2}{|c|}{ Group A } & \multicolumn{2}{|c|}{ Group B } & \multicolumn{2}{|l|}{ Total } & $\begin{array}{l}\text { Statistical } \\
\text { inference }\end{array}$ \\
\hline & $\mathbf{N}=\mathbf{6 0}$ & $\%$ & $N=60$ & $\%$ & $\mathrm{~N}=120$ & $\%$ & \multirow{3}{*}{$\begin{array}{l}\chi^{2}=0.711 \\
\mathrm{P}=0.399 \\
\text { Not } \\
\text { significant }\end{array}$} \\
\hline $\begin{array}{l}\text { Expectant management with desired control } \\
\text { of blood pressure }\end{array}$ & 47 & $78.3 \%$ & 43 & $71.6 \%$ & 90 & $75 \%$ & \\
\hline $\begin{array}{l}\text { Early termination before } \\
\text { onset of labour due to severe preeclampsia }\end{array}$ & 13 & $21.6 \%$ & 17 & $28.3 \%$ & 30 & $25 \%$ & \\
\hline
\end{tabular}

Table 5: Comparison of SBP, DBP and MAP at the time of diagnosis and after antihypertensive treatment for 1 week.

\begin{tabular}{|llllll|}
\hline \multicolumn{2}{|c|}{$\begin{array}{l}\text { Group A Nifedipine }(\mathbf{n}=\mathbf{6 0}) \\
\text { Mean } \pm \text { SD }\end{array}$} & $\begin{array}{l}\text { Group B Labetalol }(\mathbf{n = 6 0}) \\
\text { Mean } \pm \text { SD }\end{array}$ & After treatment \\
\hline & On diagnosis & After treatment & On diagnosis & value \\
\hline SBP & $155 \pm 9.8$ & $140 \pm 5.6$ & $153 \pm 9.4$ & $142 \pm 6.5$ & Not \\
\hline DBP & $106 \pm 8.9$ & $88 \pm 8.1$ & $101 \pm 8.1$ & $89 \pm 8.2$ & significant \\
\hline MAP & $122 \pm 8.9$ & $105 \pm 6.9$ & $119 \pm 8.2$ & $106 \pm 6.5$ & \\
\hline & Statistically significant & Statistically significant & & \\
\hline
\end{tabular}

Table 6: Side effects of drugs.

\begin{tabular}{|lllll|}
\hline \multirow{2}{*}{ Drug side effects } & Group A & & Group B & ( \\
\cline { 2 - 5 } & $\mathbf{N = 6 0}$ & $\mathbf{\%}$ & 0 & $\mathbf{N}$ \\
\hline Giddiness & 3 & $5 \%$ & 2 & $3.3 \%$ \\
\hline Palpitation & 2 & $3.3 \%$ & 0 & $0 \%$ \\
\hline Headache & 4 & $6.6 \%$ & & $0 \%$ \\
\hline
\end{tabular}

Table 7: Distribution of cases according to mode of delivery and gestational age.

\begin{tabular}{|lllllll|}
\hline \multirow{2}{*}{ Mode of delivery } & \multicolumn{2}{l}{ At term $>$ 37 } & weeks & \multicolumn{2}{l|}{ Pre term $<\mathbf{3 7}$ weeks } & \multicolumn{2}{l|}{ Total } \\
& Group A & Group B & Group A & Group B & Group A & Group B \\
\hline Caesarean section & 9 & 9 & 11 & 14 & 20 & 23 \\
\hline Normal delivery & 38 & 34 & 2 & 3 & 40 & 37 \\
\hline
\end{tabular}


Table 6 shows that in Group A 3 patients had giddiness, 2 patients had palpitation and 4 patients had headache after receiving tablet nifedipine. In Group B only 2 patients had palpitations after receiving tablet labetalol.

Table 7 shows that in Group A 20 patients delivered by caesarean section in which 9 were after term whereas 11 patients delivered pre term. In Group B 23 patient delivered by caesarean section in which 9 were after term whereas 14 patients delivered pre term. In Group A 40 patient delivered by normal delivery in which 38 were term whereas 2 were pre term. In Group B 37 patients delivered by normal delivery in which 34 were term whereas 3 were delivered preterm.

\section{DISCUSSION}

All 120 cases were studied on basis of age of patient, parity, gestational age at the time of onset of preeclampsia and delivery, side effects of drugs, mean blood pressure control, and mode of delivery.

This study Table 1 shows that majority $(51.6 \%)$ of patients included in the study were young ( $<25$ years) Which shows incidence is high in young women. Table 2 shows that majority $(54 \%)$ are primigravida. So, it suggests that preeclampsia incidence is highest among primigravida. In a study by Hungarga US et al and Ganesh SK et al, also had maximum patients were primigravida and below 25 years of age..$^{7,8}$

Table 3 suggest that onset of preeclampsia is less common before 33 weeks in this study (28.3\%) and maximum patients were having onset of preeclampsia between 33-37 weeks of gestation (54.2\%) and $17.5 \%$ patients had onset after 37 weeks of gestation. Hungarga US et al, conducted study also had maximum patient who developed preeclampsia during 35-40 weeks of gestation which has similar findings as this study. ${ }^{8}$

In this study as shown in Table 4 in Group A 47 patients $(78.3 \%)$ and in Group B 43 patients $(71.6 \%)$ had desired control of blood pressure during expectant management and continued till spontaneous labor pain, whereas 13 patients in Group A and 17 patients in Group B required early termination before onset of spontaneous labor either induction or LSCS due to development of severe preeclampsia. This difference is not statistically significant $(\mathrm{p}=0.399)$. As pregnancy advanced during expectant management Group B had slightly higher rate of conversion to severe preeclampsia and need of early intervention than Group A (28.3 versus 21.6).

As shown in Table 5 after continuation of antihypertensive for 1 week in Group A average SBP reduced from $155 \pm 9.8$ to $140 \pm 5.6$ and DBP reduced from $106 \pm 8.9$ to $88 \pm 8.1$ and MAP from $122 \pm 8.9$ to $105 \pm 6.9$. And in Group B average SBP reduced from $153 \pm 9.4$ to $142 \pm 6.5$ and DBP reduced from $101 \pm 8.1$ to $89 \pm 8.2$ and MAP from $119 \pm 8.2$ to $106 \pm 6.5$. Both the group had almost similar effective desired control and had almost similar reduction in blood pressure after 1 week of drug therapy. Statistically it is confirmed that both the drugs significantly reduce blood pressure. Statistically both the group shows very minimal difference which is not significant. Compared to Group A there was slightly less sustained control of blood pressure leading to early termination in Group B which is also statistically insignificant.

In study by Rose DT et al, shown in their study that both the drug labetalol and nifedipine has equal efficacy in reducing blood pressure in preeclampsia. ${ }^{9}$ Whereas contrary to this study, study by Shekhar et al and Dhali B et al has concluded that nifedipine is more effective in reducing blood pressure. ${ }^{10,11}$

Although both the drugs have acceptable safety profile in pregnancy, Table 6 shows that insignificant numbers of patient had side effects like palpitation giddiness and headache in Group A who had received nifedipine, which was subsequently reduce after some time by itself or with dose adjustment, whereas no patient had side effects in Group B who had received labetalol.

In this study authors found that Group B patients who received tablet labetalol had slightly higher rate of delivery by cesarean section and pre term delivery than Group A patients who received tablet nifedipine but the difference is not statistically significant.

\section{CONCLUSION}

In spite of recent advances and studies preeclampsia is still major cause of maternal morbidity and perinatal mortality and morbidity. Management should depend on severity of hypertension as well as comorbidity. Beside delivery of fetus, the main treatment of preeclampsia is control of blood pressure by anti-hypertensive drugs.

From this study authors concluded that both the drugs labetalol and nifedipine are equally effective in controlling blood pressure with minimal side effects with nifedipine. Cost effectiveness is better with nifedipine. Although nifedipine has more sustain control of hypertension over labetalol, difference is very less. So, any of this drug can safely be used as a first line drug therapy for preeclampsia. But larger scale and long-term study is required to reach to conclusion.

Funding: No funding sources

Conflict of interest: None declared

Ethical approval: The study was approved by the Institutional Ethics Committee

\section{REFERENCES}

1. Ghulmiyyah L, Sibai B. Maternal Mortality from Preeclampsia/Eclampsia. Seminars Perinatol. 20125;36(1):56-9. 
2. Say L, Chou D, Gemmill A, Tunçalp Ö, Moller AB, Daniels J, et al. Global causes of maternal death: a WHO systematic analysis. Lancet Glob Health. 2014;2(6):e323-33.

3. von Dadelszen P, de Campos DA, Barivalala W. Classification of hypertensive disorders of pregnancy. The FIGO Textbook of pregnancy hypertension: an evidence-based guide to monitoring, prevention and management. London: Global Library of Women's Medicine; 2016:33-61.

4. APEC guideline: Pre-eclampsia. In: Aabama perinatal excellence collaborative guidelines, Protocol, 2020. Available at: http://apecguidelines.org/guideline/preeclampsia/. Accessed on $10^{\text {th }}$ March 2020.

5. American College of Obstetricians and Gynecologists. Hypertension in pregnancy. Report of the American College of Obstetricians and Gynecologists' task force on hypertension in pregnancy. Obstet Gynecol. 2013;122(5):1122.

6. Odigboegwu O, Pan LJ, Chatterjee P. Use of antihypertensive drugs during Preeclampsia. Front Cardio Med. 2018;5:50.

7. Ganesh SK, Unnikrishnan B, Nagaraj K. Determinants of preeclampsia: a case control study in a district hospital in south India. IJCM. 2010;35(4):502-5.

8. Hangarga US, Rita D, Harshitha K. Comparative study of labetalol and Nifedipine in management of hypertensive disorders in pregnancy. Int $\mathbf{J}$ Reprod Obstet Gynecol. 2017;6:194-7.

9. Rose DT, Jeyarani P. Comparative study of labetalol and nifedipine in management of non-severe preeclampsia and its fetomaternal outcome. Int J Reprod Contracept Obstet Gynecol. 2019;8(5):2035.

10. Shekhar S, Sharma C. Oral Nifedipine or intravenous Labetalol for hypertensive emergency in pregnancy: a randomized control trial. Obstet Gynecol. 2013;122(5):1057-63.

11. Dhali B, Bhattacharya S, Ganguly RP, Bandyopadhyay S, Mondal M, Dutta M. A randomized trial of intravenous labetalol and oral nifedipine in severe pregnancy induced hypertension. Int J Reprod Contracept Obstet Gynecol. 2012;1(1):42-6.

Cite this article as: Patel AR, Arora SR, Bhatt JK. Comparison of oral nifedipine and oral labetalol as a single drug therapy for control of blood pressure in preeclampsia. Int J Reprod Contracept Obstet Gynecol 2020;9:2328-32. 